\title{
CIRCULATING IGNORANCE: Complexity and Agnogenesis in the Obesity "Epidemic"
}

\author{
EMILIA SANABRIA \\ Ecole Normale Supérieure de Lyon \\ (D) http://orcid.org/0000-0002-5595-7905
}

I log into Skype with the usual hesitancy - is 2 p.m. GMT noon or 1 p.m. in France? I am joining the monthly Executive Committee (EC) call of the World Public Health Nutrition Association (WPHNA), along with colleagues in Australia, Brazil, Ghana, Norway, South Africa, and the United Kingdom. The agenda is full, owing to the upcoming International Conference on Nutrition (ICN2). ${ }^{1}$ For nearly a year, the association, along with others, has been engaged in the delicate exercise of proposing modifications to the draft Framework for Action that United Nations (UN) member states will endorse at ICN2. Today we discuss the loss of a footnote pertaining to the technical definition of a "healthy diet." One prominent anti-sugar advocacy group wants to see this defined as a diet in which only 5 percent of calories come from added sugar. ${ }^{2}$ There are a few weeks to go still, but ICN2's political reach already feels compromised. Agenda point 3 of our meeting asks whether the association should sign a letter to appear in the Lancet expressing its support for a global convention on nutrition, one modeled on the Global Framework Convention on Tobacco. The hope is that ICN2 may lead to a legally binding international framework to address global malnutrition, which in the twenty-first century includes competing rates of hunger and obesity. Today, our discussion turns on how the term nonstate actors adopted by the UN lumps together BigFood corporations, health agencies, patient associations, and civil society organizations defending small-scale farmers or human rights. "Busi- 
ness," one senior member of the EC notes, is being granted "inappropriate access" to the meeting, and using this undue influence to lobby against a legally binding framework convention. Everyone shares anecdotes about behind-the-scenes lobbying they have observed in their various positions. Much of it pertains to semantics: pushing for individual responsibility where market regulation is discussed, advocating a need for "just more food" when nutritional quality or changes to the food system are invoked. ${ }^{3}$ The WPHNA is fairly unique in its approach. Although it is mainly constituted of medically trained nutritionists, it subscribes to a vision that sees nutrition as a political as much as a biological phenomenon. For the WPHNA executive, this implies critically engaging with the way in which scientific evidence is deployed in the field of nutrition and questioning the role BigFood plays in addressing global malnutrition.

\section{IGNORANCE, DESIGNED AND PERVASIVE}

This article examines the things that are said to be un/known about obesity and the way in which attributions of knowledge or ignorance circulate within the field of public health nutrition. I have been struck by experts' focus on knowing more and building better evidence bases, even as they reflect on how much is not known about obesity. What does this focus on knowing obfuscate? The knowledge constructed in expert meetings and scientific forums provides the contours of possible public health interventions addressing obesity. Such framings recast not just what is known (or not yet known) but also what is knowable. My article draws on recent work on the social construction of ignorance (Croissant 2014; Geissler 2013; Kelly and Beisel 2011; McGoey 2012; Pinto 2015; Proctor 2011) to argue that the field of evidence in obesity science is fashioned in a way that deflects attention (and responsibility) away from questions of food production, distribution, and marketing and continues to frame the problem as one of individual responsibility. I analyze the variegated forms of un/knowing that arise from my observations concerning the operational problems of contending with complexities and uncertainties in the field of obesity science to attend to the politics at stake in the maintenance of distinctions between knowledge and ignorance.

Recent work in social theory has turned attention to how unknowing is not simply the absence of knowledge; rather, it may be actively produced by social practices. The term agnotology has been coined to refocus attention away from what we know and how we know to what we do not know and why (Proctor and Schiebinger 2008). It broadens the focus given to the social construction of knowledge to include analyses of the social production of ignorance. Linsey 
McGoey's (2007) analysis of "strategic ignorance” shows, for example, how willful blindness on behalf of the pharmaceutical industry constitutes a strategy used to exonerate it from the need to take action. Uncertain, complex, contradictory, or competing scientific facts may be mobilized as political capital or rhetorical tools that shift blame, as those communicating ignorance are excused (Oreskes and Conway 2011). Earlier analyses of agnogenesis, or the production of ignorance (Pinto 2015, 296), focused on the instrumental production of ignorance for corporate profit. While important in revealing the impact of the neoliberalization and industrialization of scientific research (Hess 2015), such studies implicitly assume that this is bad science and that transparency would reduce scientific ignorance (Frickel and Edwards 2014; Pinto 2015). Yet ignorance is a somewhat inevitable and at times positive feature of scientific activity and organizational labor (Croissant 2014; Gross and McGoey 2015). The more guileless production of ignorance resulting from organizational processes is - or can be-thoroughly embroiled with willful intent to create strategic opportunities from this decoupling of facts (Heimer 2012). Recent work on ignorance departs from the normative assumption that science deals in certainty and points to the fact that the very process of scientific research, from experimental design to data analysis and publication norms, have been shaped from within by decades of industry-funded research. Ignorance reigns not (only) because transnational corporations secretly produce doubt but also because the epistemic form that science has acquiredits evidentiary norms, reductionist underpinnings, and emphasis on causality and quantification - render many relations invisible (Kleinman and Suryanarayanan 2015). David Hess (2015) proposes the notion of "undone science" to move past accounts that locate the instrumentalization of uncertainty in vertical relations between scientific elites and disempowered publics or their governments. Undone science refers to those known unknowns that civil society organizations highlight as having potential public benefit but that industrial elites may actively seek to elide through their influence on what Hess $(2015,142)$ calls "the political opportunity structure of research funding." As Manuela Pinto $(2015,310)$ notes, at stake is a discussion of the epistemic and social goals of science, against which practices of ignorance construction can be measured.

Governments, corporations, or international agencies often appeal to available evidentiary regimes to support their actions, but such appeals to the neutrality of evidence prove highly problematic. Critical scholars are calling attention to the fact that scientific evidence concerning public health interventions constitutes only one voice in a much larger conversation. They systematically review the repertoire 
of actions adopted by corporations to mold or landscape the field of evidence and strategically orient scientific debate and policy options (Hawkes and Buse 2011, Moodie et al. 2013; Proctor 2011; Stuckler et al. 2012; Ulucanlar et al. 2014). The intricate links between transnational food corporations and nutrition experts in key governmental and UN decision-making roles across the globe are well established (e.g., Gornall 2015; Moodie et al. 2013). What is more difficult to ascertain is exactly how this connection shapes the knowledge that researchers are producing or inflects the decisions they make as experts. One analysis found that industry-funded studies (or those reporting conflicts of interest) were five times more likely to report a conclusion of no positive association between softdrink consumption and weight gain than those with no declared industry funding (Bes-Rastrollo et al. 2013). Robert Proctor (2011) documents how the tobacco industry has not just corrupted scientific knowledge about tobacco risk but shaped it from within, through decades of ties between industry and research. Each piece of industry-sponsored research may appear perfectly unbiased at the micro level, but the scale of the tactic becomes evident when such "purchased engagement with public health" is multiplied globally (Gornall 2015). Similarly, writing on the pharmaceutical industry's use of scientific ghostwriting, Mario Biagioli (forthcoming) shows how, taken individually, each peer-reviewed piece is technically not fraudulent, though the net cumulative effect shifts the knowledge base in a direction favorable to corporate interests.

Rather than discrediting the veracity of the evidence produced in industryresearch partnerships, this article shows how the consensus forged in conferences and policy spaces concerning the uncertainty and complexity of obesity's determinants creates a continued deflection of responsibilities back to the purported knowledge deficiencies of individual eaters. There are stakes in narrating these forms of ignorance - those imputed or strategically kept out of public debate by agrofood business lobbies - together. Keeping the stories apart produces an absence that obscures the labor of making them appear unrelated. I bring together a series of ethnographic observations from policy spaces, scientific forums, and international advocacy groups in which the downplaying of industrial responsibilities and the overemphasizing of individual responsibilities to know about healthy eating becomes particularly clear. By bringing these variegated forms of nonknowledge together, the article examines the deflections of responsibility at play between individuals deemed ignorant and a food industry highly active in downplaying its role in the obesity epidemic. I present a range of analyses arguing that this represents a deliberate strategy on the part of corporate actors. 
My intervention here also means to move beyond this observation to show how the structuring of the field of evidence, the possibility of reliably showing causal relations between the political and socioeconomic determinants of malnutrition and measurable health indexes is largely compromised not simply by the absence of good evidence but also because the existing parameters of good science cannot straightforwardly reveal such relations. This is because the configuration of the knowable is increasingly defined in terms of whether knowledge is actionable (as determined by the logic of evidence-based medicine eloquently described by Vincanne Adams [2013]). Obesity, like many of today's complex problems, results from phenomena spanning multiple scales and determined by myriad nested interactions, from the political economies of market regulation to the modes of agricultural production, the biochemistry of appetite regulation, urban planning, changing family structures, meal patterns, and labor forms. Yet despite growing recognition of the problem's heavy overdetermination (e.g., U.K. Government Office of Science 2007), public intervention - and the science produced to guide or validate such intervention - remains wedded to a mode of reading and intervening that has limited purchase on the complexity with which it contends. The epistemic regimes that dominate the field of public health (and many other areas of public policy) frame complex problems in a manner that reduces them to what is manageable, even when such framings are contested or shown to be inadequate. Complex conditions resist explanation within extant modes of knowing. Writing on how it is that we continue to ignore many of the effects of toxics, Kim Fortun (2012, 452) suggests that this inattention derives from a tendency to rely on established idioms and ways of thinking, although these do not grasp the problems at hand. For example, ignorance is produced when the idioms and thought styles of mechanics are imposed on toxics. No evidence of harm emerges "because the evidence deemed necessary is at odds with the condition it is meant to represent." This state of affairs demands our urgent and critical engagement with the specific meaning of evidence.

\section{OBESITY AND THE FRENCH PARADOX}

Obesity rates did not rise as rapidly in France as elsewhere. In the wake of the so-called globesity epidemic, many experts puzzled over this seemingly French paradox: how could the French remain slim despite their gastronomic traditions, three-course meals, hundreds of cheeses, and boulangeries full of irresistible pastries? Yet over the last decade, French obesity rates have caught up with those of France's European neighbors. As a consequence, three major public health initia- 
tives were launched to tackle noncommunicable chronic diseases associated with high body-mass indices (BMIs). Such initiatives often revolve around the idea that controlling weight involves willpower and choice; they also tend to focus on nutrition education and information. Within this model, people receive information, are expected to understand it, and to change their behavior accordingly. As Deborah Prentice $(2015,266)$ puts it: "Ignorance is a popular explanation for dysfunctional behavior." Health education interventions are often limited to a fairly unidirectional process of information transfer from a knowledgeable educator to a purportedly ignorant individual. This approach implicitly assumes that knowledge makes for a sufficient condition to bring about modified behavior, overlooking the possibility that economic conditions, work rhythms, access to healthy foodscapes, or the commensal dimension of eating might constrain the application of knowledge about nutrition.

Obesity has been made into a highly visible issue globally. Think of the news reports and documentaries depicting the headless obese bodies thought to populate contemporary landscapes or the exponential growth curves depicting global obesity trends and rising rates of cardiovascular disease. The BMI surreptitiously provides a numerical valence to what is apparently plain to see. It provides clinicians with a tipping point, albeit one whose global standardization led millions to move from overweight to obese overnight, without gaining so much as a pound. As elsewhere, French public health programs targeting obesity characterize it as an epidemic, although the epidemiological data to support this claim remains disputed (Gard 2011). The surveillance tools at work in French preschools now enable health workers to identify "future obèses [obese persons]" even before they move out of the normal weight range. This feat of making the future obese child visible is accomplished with a simple measurement tool with which all French children are now screened. It involves mapping the so-called adiposity rebound, which is a rise in BMI that occurs between the ages of three and seven years. An early adiposity rebound is said to constitute a risk factor for obesity later on in life. As one school nurse told me: "It's a marvelous tool; you can literally see the future obèse before he gains the weight." But what do such representations obscure? Clare Herrick $(2009,57)$ points to the disjuncture between the complexity and uncertainty surrounding obesity's etiology and the apparent display of confidence in advancing evidence of ever-rising rates of obesity, making for a unique health crisis that has attracted hyperbolic public attention.

I draw on materials gathered in the context of my research on alimentary health in France (Sanabria 2015; Sanabria and Yates-Doerr 2015) and on a ret- 
rospective ethnographization (see Ingold 2014) of my encounters with colleagues at the WPHNA and in my (French) workplace, where I was hired to carry out anthropological research in the field of health education. This article refracts a series of global questions concerning the circulation of ignorance in the construction of evidentiary regimes of nutritional interventions through a range of materials collected in France and through my participation in global forums such as the WPHNA. As such, I do not purport to provide an ethnographic description of obesity in France as much as to situate the problem within a specific ethnographic setting. ${ }^{4}$ The issue I attend to is difficult to locate as it is raised by a subgroup of vocal but globally dispersed critical public health nutrition advocates, with some of whom I have been collaborating since I joined the WPHNA's Executive Committee in 2013. If anything, what is specific to the French situation is the absence of the debate from the public arena. My article draws on observations gathered at numerous French policy meetings, expert workshops, and conferences on how to change les comportements alimentaires (eating behaviors), as well as on a review of published literature on public health nutrition interventions.

\section{BEYOND KNOWLEDGE AND ITS ABSENCE: Health education and behavior change}

The French National Program for Nutrition and Heath (PNNS) identifies "information education communication" (IEC) as its main strategic lever to shape food behaviors. Yet despite considerable investment in such campaigns, obesity rates continue their progression, leading some to suggest that this represents a weak strategy in the face of our strong biological drive to seek out and enjoy calorie-dense foods (Brownell and Gold 2012; Kessler 2009). Today, the idea that education through the conveying of messages could impact health behaviors seems quaint. Traditionally, health education was premised on a hierarchical model of knowledge transfer in which ignorant individuals were deemed incapable of making appropriate health decisions. The WHO's 1986 Ottawa Charter highlighted the importance of making all governmental policy - from urban planning to housing, employment, and transport - "healthy." Yet the majority of governments have taken the easy (and cheaper) route of reducing health promotion to health education and social marketing (Bergeron, Castel, and Nouguez 2013; Nutbeam 2005; Whitehead and Irvine 2011). Despite the emerging recognition that informing has not worked, IEC models of health education remain entrenched and continue to mobilize attention among experts. In the absence of a magic bullet, targeting health behaviors through education is seen as the sole option. 
This point was put quite bluntly to me during a research meeting that explored possible lines of collaboration to identify, in one senior nutritionist's words, how best to éduquer les comportements alimentaires (educate health behaviors) to prevent obesity. The meeting followed a tour of a ward in a major hospital in the south of France where "morbid" obesity is tackled. With little success, as the intern noted, given that the patients "qui échouent là [who wash up here]" return to the same real-life problems after the ward, where they cannot apply health recommendations. More used to working in Brazilian public hospitals than French ones, I was stunned to observe contrasts not unlike those I had so often witnessed in Brazil: the blatant disparities between thin, well-to-do, white middle-class health professionals and the patients on the wards, who were of mixed rural and immigrant origins and whose stories and bodies attested to lives lived in precarity. "Until we get better epidemiological support for bariatric surgery, all we can do is éduquer nos obèses [educate our obese persons]," the chief consultant (who receives, as many French nutritionists do, funding from the Fondation Nestlé and other, less explicitly named corporate entities) concluded.

The medical team is acutely aware of the social dimensions of the problem. "Some [patients] don't even have a dining table!" the intern exclaimed. These patients just microwave their food and eat in front of the television (which, in France, is often referred to as an Americanization of eating). Social inequalities, maximizing the calorie per euro ratio, and lack of education constituted the main determinants of the issue, in the medical practitioners' view. This insight in some respects represents a positive step, laying the groundwork for better cross-disciplinary understanding between medical professionals and anthropologists. But as my colleague and I returned to the stories we had just heard, which revealed more patient knowledge of nutritional recommendations than doctors often recognize and which pointed to the challenges of eating a balanced home-cooked diet when working les trois-huits ${ }^{5}$ or struggling to resist foods that were simply everywhere, we were cut short by the consultant: "It's all well and easy for you to evoke the endless determinants and say it's more complicated, but we have people dying of obesity and we need answers we can put into practice."

One series of answers sought by nutritionists surrounds how to motivate behavior change through education, and social scientists such as myself have been called on to help operationalize this. As might be expected, the particular set of meetings I am describing ended without us identifying a common rationale. But it made me appreciate afresh the clinician's sense of urgency and the disjuncture between the knowledge we as anthropologists produce and the kind of knowledge 
that might be required in the day-to-day life of the clinic. Literacy, knowledge acquisition, information, and education are relatively interchangeable in these contexts. Yet changed behavior does not flow, linearly, from information transfer. Critical health pedagogues have shown that reducing education to information transfer does little more than attribute ignorance to others, rendering them passive recipients of pedagogical endeavors (Fitzpatrick and Tinning 2014). Although French nutritional health educators increasingly recognize the insufficiency of information transfer alone, developing interventions that extend beyond it risks being dismissed as cumbersome, expensive, or based on uncertain evidentiary regimes. In the schools in which I have observed nutritional education, these endeavors seldom amount to more than testing a student's ability to list food groups and rehearse the health messages dispensed in national food guidelines (and made known to young people principally through the health warnings on the “junk" foods heavily marketed to them). "It's a bit of a lost battle," one school nurse told me as we discussed the challenges of nutritional education in the corridor while the students played an online game about nutrition as part of their civics and health education curricula. Although growing consensus exists about the need for a change in nutritional behaviors, how it is to be achieved (according to whose definition and with what means) remains an open question.

As I circulate through spaces where the work of rendering obesity interventions (measurably) implementable is carried out, I find myself further removed from the urgencies of tackling morbid obesity or navigating euphemisms to avoid stigmatizing overweight adolescents in the classroom. One morning I attend an expert meeting in Paris on nutrition and chronic disease, where a senior civil servant from the Assurance Maladie (the health branch of France's social security system) is giving a speech that thoroughly confuses health promotion and disease prevention. Monsieur Dupont spoke of promoting individual responsibility for health, "not to place the blame on obese people but to enable them to become stewards of their own health." Dupont has developed a program called Active Health Coaching. Coaching, in France, evokes to many left-wing defenders of public health the worst of neoliberal ideologies, with its individualization of responsibility and its privatization of structural and societal issues. His tone at the meeting is deliberately provocative, implicitly targeting such leftist critiques: "We spend 11 million [euros] on diabetes alone. We're driving into a wall. That's OK, but not while we're honking our horn and not with me at the wheel." Active Health Coaching is still in its trial period, but it signals an interesting move in the French social security system. 
I later met with several Active Health Coaching program managers in the pristine Assurance Maladie headquarters in Versailles. There are blurred rationales underlying the program's development, I realized, as we sipped oversweetened coffee from disposable plastic cups. Economics transpires behind the language of empowerment; "I know it's not politically correct to say so when you work for the Assurance Maladie, but we need to start saving," Dupont told me. Coaching is done in groups, a local program manager explained, because it creates a "ripple effect" and because it is cheaper than individual coaching. Information remains crucial: members who sign up for the Active Nutrition program go through a motivational interview in which they commit to four obligatory "information workshops." The interview serves to weed out "those for whom we can't do anything," the manager clarified, so that they do not take up a "space that can be given to a motivated obèse; this is public money after all." Public money invested into expensive real estate, with modern shop fronts and dedicated hostesses "to shake off the dusty image of the Assurance Maladie," another manager boasted. Not everyone shares this vision of change, of course. As one Assurance Maladie employee from the much less prosperous Saint-Denis neighborhood noted: "They are opening flashy agencies and personalized e-coaching with dubious behaviorchange experts, while closing local branches and suppressing face-to-face contact in the places where it is most needed."

As elsewhere, neuromarketing and nudging are on the rise in French public health circles (e.g., Oullier and Sauneron 2010). Neuroprévention, as it is dubbed, draws on the "new" behavioral economics to reveal that individuals are also driven by unconscious factors (Rice 2013). The "naive informational model of health education has failed," a senior health economist stated during the opening session of a meeting of French policymakers gathered to identify new levers for change in nutrition. After a welcome buffet featuring the event's industrial sponsor's new "healthy," vacuum-sealed, diabetic-friendly breakfast bar (but no fruit, another attendant noted with a wink), the meeting kicked off with a talk by a neuroscientist and the director of France's largest marketing research institute. He presented data on the importance of unconscious processes in driving behaviors modeled on "real-life shopping experiments." Consumers make choices in a fraction of a second, he informed us, without any cognitive engagement. "To target reason is to miss the decision [making]." It is telling of the shifts underway that the meeting's organizers would have a marketing director address an assembly of policymakers, doctors, and researchers gathered to identify levers for change in nutrition. As the director told us: "I help my clients [PepsiCo, Danone, Unilever, 
and Kraft, according to his declaration of interests] sell more. The ethics are your bit.”

Unconscious drives occupy a curious place between knowledge and its absence. Such an intrusion (as behavioral economists often present it) of the prerational has a complicated relation to knowledge and lack thereof. It is based on a distinction, introduced by Daniel Kahneman (2011), between two systems of knowing: one rational and logical, the other intuitive and perceptual. Health education and most obesity-prevention strategies focus on the rational system, which processes new information against existing knowledge. Yet the intuitive system takes new information at face value, such that Deborah Prentice (2015, 267) suggests it is an open question as to whether this system can experience ignorance. The second system always knows something, even if the knowing is biased, partial, or skewed. "Misknowledge" (Prentice 2015) operating at this level interferes, in the view of behavioral economists, with the rational mind's capacity to translate knowledge into action. Public health interventions have essentially targeted the rational mind, providing it with information that in the emergent competing view cannot be operationalized because of the irruption of precognitive drives. Here, we have an interplay between forms of unconscious knowing, on the one hand (such as the affective drives seen to impede rational decision-making capabilities) and forms of strategic ignorance, on the other. This is all the more troubling when we consider that tools developed to sell more calorie-dense foods are now being marketed to public health experts to redress the deleterious impact of the massive increase in consumption of these foods. Considering that the food industry's budget to deploy these marketing tools is nearly tenfold that invested annually by governments in health promotion, the battle may not just be lost but in fact unwinnable.

\section{A CIVIC (INDIVIDUAL) RESPONSIBILITY FOR HEALTH?}

Sheila Jasanoff $(2005,258)$ proposes the term civic epistemologies to refer to how publics know things in common. Such public knowing varies between national contexts as knowledge is presented, tested, and put to use in public arenas. The concept of civic epistemologies poses public life as a "proving ground for knowledge claims and as a theater for establishing the credibility of public actions." The expert meetings and conferences I describe here can be thought of as theaters of civic epistemologies. They are not policymaking spaces as such, for this labor takes place elsewhere, in ministerial cabinets. Nor can they really be conceived as spaces of public accountability, for the publics that they bring together consist 
of experts, research funding agencies, policymakers, and health professionals vested in addressing nutrition-related health issues. These spaces collectively enact a problem space around obesity, and they outline the contours of possible interventions. As such, they are spaces in which the constitutive dimensions of civic epistemologies about obesity are enacted. The knowledges that circulate here draw eclectically on various disciplines and do not map neatly onto those at work in the more formal scientific arena. Claims about rendering specific interventions operational become legitimized through an active investment in such spaces. It is in and through them that a specific (French) rendition of the individual's civic responsibility for health is constructed and enlivened.

On a rainy winter morning, a group of representatives from the PNNS, the Plan Obésité (Obesity Plan), the Assurance Maladie, and the Mutualité Française, ${ }^{6}$ came together with academic researchers in the Parisian headquarters of a leading nonprofit health insurance company to discuss the relative costs of nutritionrelated chronic conditions, as well as the contours of different strategic interventions. The Mutualité Française's representative began her presentation by stating that more than 8 million French people are supported under a chronic disease regime. While this represents only 12 percent of the population, it accounts for more than 65 percent of national health costs. At stake, she poignantly argued, is the continued existence of France's social security model: "If costs continue to rise, our system of solidarity will be called into question.” As a spokesperson for the French nonprofit mutuelle system of health insurance, she was no neutral commentator on the importance of addressing social inequalities and the sustainability of France's model of social solidarity. From her point of view, the unsustainable costs incurred because of chronic disease made overweight people a direct threat to France's social contract. It seemed ironic to hear this defender of social equality speak of "the problem that the obese lay on our system." Likewise, the representative from the Direction Générale de la Santé of the Ministry of Health and Social Affairs noted the costs of obesity-related disease: "15 billion [euros] a year weighs heavily on public accounts. We can reduce this with preventative education targeting the obese." In the long list of burdens "the obese" apparently place on society, the toll they take on solidarity and social cohesion makes for a striking addition. This language points to lines of fracture among who is amenable to solidarity, who is included, and how it is gauged.

In Cruel Optimism, Lauren Berlant $(2011,98)$ invites us to consider the distribution of agency assumed in national instantiations of public health imaginaries. She interrogates the paradoxical coexistence of an "attrition of the subject" 
and of normative notions of agency that assume the subject will, can, or should care for herself. Berlant describes how liberals (in the U.S. sense of the term) seek to reclaim the state as a reparative resource in the face of a deregulated market circulating unhealthy commodities, while conservatives denounce such measures as those of a "communist" or "nanny" state. This approach provides an interesting foil to the situation I am describing. Viewed from France, the U.S. debates around Obamacare are almost incomprehensible. In France, North American calls to charge obese persons more for their health care are often held up as emblematic of national differences in relations between the state and its citizens. This renders the statements that circulated at the expert meeting described above striking, as they point to an attrition of the French social contract in relation to obesity. In the French context, the problem is framed not in terms of paying for those who have brought ill health on themselves, but rather in terms of an intolerance toward obesity-incurred health costs threatening French social security. ${ }^{7}$

There are important stakes in how a problem and its solution are framed. What counts as part of the story of obesity is highly political. Having outlined how many public health interventions continue to hold individuals responsible, I now examine how the field of evidence is landscaped to enhance the promissory value of certain interventions over others. I suggest that strategic ignorance (McGoey 2012) may purposefully obscure or overemphasize the relative implementability or efficacy of interventions and show that this often serves the purpose of deflecting responsibilities back onto individuals.

\section{COMPLEXITY, UNCERTAINTY, AND THE SCALAR LOGICS OF PUBLIC HEALTH NUTRITION}

A common feature of the presentations given in policy circles on chronic disease or obesity prevention is the graphic representation of factors affecting health outcomes and the scales at which interventions should be designed. Many of the models used in these contexts are variations of the socio-ecological framework of health.

These models give a visual representation of the classic set of categories that appear in the literature on health promotion. The models depict concentric circles and place the individual at the center of consecutive layers of interpersonal, community, organizational, or policy influences. They obscure interactions between these predefined spheres and reveal the importance of the modern, rational individual decision-maker for public health. Many accounts of the complex problem of malnutrition cannot be accommodated by these models and their reified 


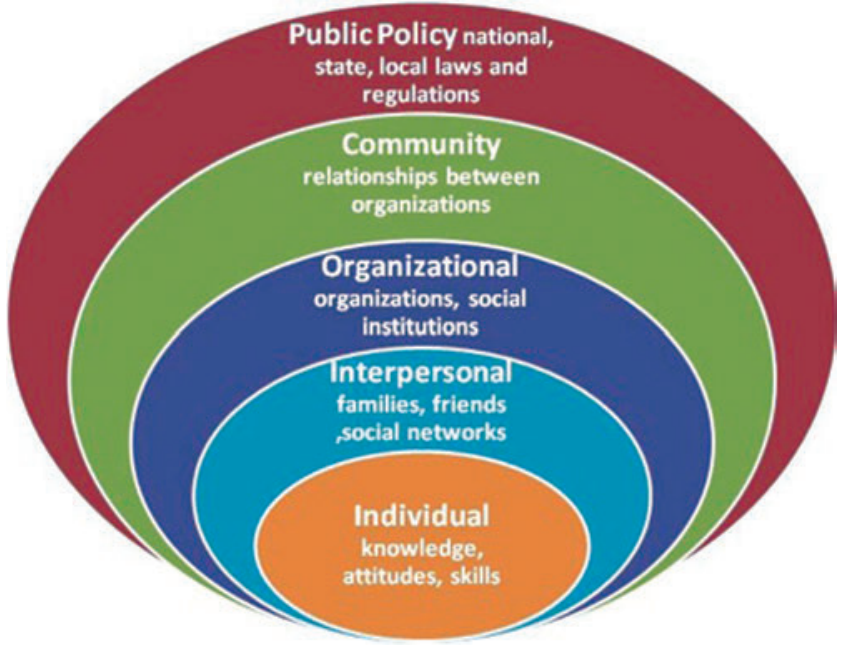

Figure 1. One variant of the socio-ecological framework of health promotion. Uncredited slide.

categories. One such account considers the growing availability of processed hyperpalatable foods in urban environments as a major factor in the rise of obesity. Hyperpalatability refers to the fine-tuning of foods by the industry to enthrall the senses, override satiety, and motivate eaters to pursue more (Kessler 2009). This phenomenon collapses the scalar relations between categories such as body, individual, environment, or political-legal regulation. Here macroeconomic forces - such as trade agreements, pricing mechanisms, or the massive entrance of transnational food and beverage companies into developing world marketsdirectly target the biochemistry of appetite regulation. That is, they methodically elicit the irruption of what behavioral economists refer to as precognitive drives. In the cybernetic models used to think the relations between eaters and the environments in which they source foods, nutrients, fat cells, the gastrointestinal tract, brain regions, and pleasure receptors undermine eaters' capacities to make rational choices (Sanabria 2015). For example, in Figure 2 (variations of which increasingly appear in the expert meetings I attend), the environment influences metabolism through mechanisms such as availability, palatability, taste, and social habits. Feedback loops set by a central "metabolic brain" link it to the internal milieu, graphically represented by free-floating organs. I argue that, at present, only the first type of graphic representation informs public action.

Hannah Landecker (2013) asks after the "knowledge effects" of the growth of metabolic disorders such as those associated with obesity worldwide. She argues 


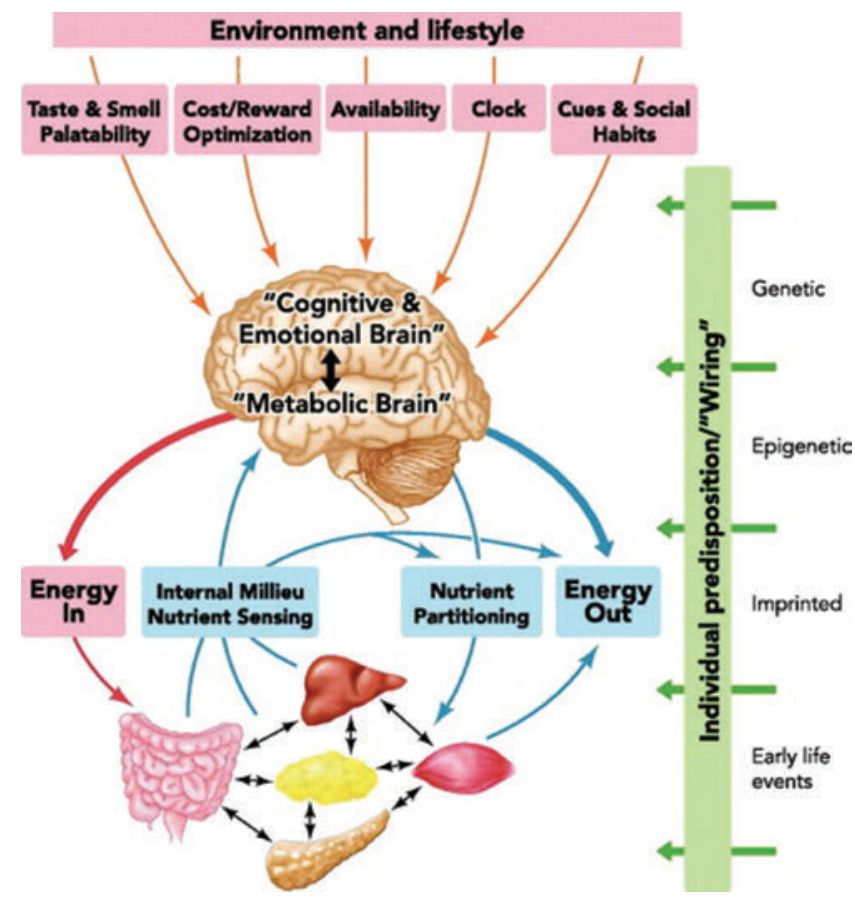

Figure 2. Schematic diagram of the major factors determining the neural control of appetite and energy balance regulation. Figure from "Neural Systems Controlling the Drive to Eat:

Mind Versus Metabolism,” by Zheng Huiyuan and Hans-Rudi Berthoud, http://dx.doi.org/10.1152/physiol.00047.2007.

that the efforts to comprehend and treat metabolic disorders are transforming our knowledge of life. The shift she traces between industrial and postindustrial metabolism makes for one way to read the changes in the graphic representations of obesity mobilized here. "Fat knowledge," or the knowledge effects of obesity, has brought about a shift in the conceptual language of metabolic research, away from the language of manufacturing and energy toward that of regulation, signal, and information (Landecker 2013, 511). Landecker (2013, 516) points out that the conditions for the growth of postindustrial metabolic fat knowledge were set by the logics of industrial metabolism and the "fattening effects of industrialization.” Likewise, Julie Guthman (2015) shows how the imbalance of food production and food consumption poses a limit to capitalist accumulation. The food industry addresses this imbalance through competitive marketing, increased food processing, and substitutionism, as well as by inducing people to eat more. ${ }^{8}$ The changes made to the material constitution of foods that exist primarily to "resolve 
a particular limit to capitalism" (Guthman 2015, 9) have many as yet unknown effects on eaters' metabolisms and the sustainability of local food systems.

The question is whether (and how) such effects could become knowable. As we saw at the outset, obesity's complexity spans phenomena operating at multiple scales. The problem of relating these often incommensurable scales in a manner that can guide interventions addressing obesity appears acutely at relevant scientific gatherings. A recent European Congress on Obesity (ECO) held in France brought together more than 2,500 international delegates around a multistream scientific program that included high-profile industry-sponsored satellite sessions. The scientific program included presentations on the clinical management and prevention of obesity, bariatric surgery, adipose tissue physiopathology, epigenetics, epidemiology, psychiatry, health economics, and social psychology. Attending such an event, one is struck by the complexity of the processes described at each scale. What relations are crafted between the ontologically different entities held in the various models, from brain parts to blood sugar measures, from experiences of hunger to the spatial politics of food distribution, from metabolic hormones to agrarian policies or reforms to the health-care system (both notable absences from ECO)? The tangible angst surrounding obesity is linked to the nature of the problem it appears to present. Putting all of these scales together gives rise to an almost absurdly complex representation. For instance, the Foresight report (U.K. Government Office of Science 2007) included the Obesity System Map, which attempts to represent this complexity. The map reveals the difficulty inherent in making policy on the basis of the proliferation of factors recognized as affecting dietary health outcomes.

Stanley Ulijaszek (2015) remarks that the Obesity Systems Map explicitly frames obesity as a complex issue that requires multiple sites of intervention beyond individual-focused health education. Whether or not this complexity exceeds that of other health problems (which also span biochemical, social, behavioral, and environmental phenomena), what is notable about the field of obesity is the way in which the arena reflexively grapples with its own complexity. In his analysis of the Obesity Systems Map, Ulijaszek draws on Chunglin Kwa's (2002) analysis of the ways in which science has approached complexity. Kwa differentiates between two models of complexity in science: the romantic and the baroque. In this schema, romantic framings of complexity are founded on the idea of hierarchical levels of organization integrated into a functional whole. Romantic complexity thus aims to provide a coherent model of complex systems by mapping the relations between constitutive elements. The baroque sensibility, on the other 


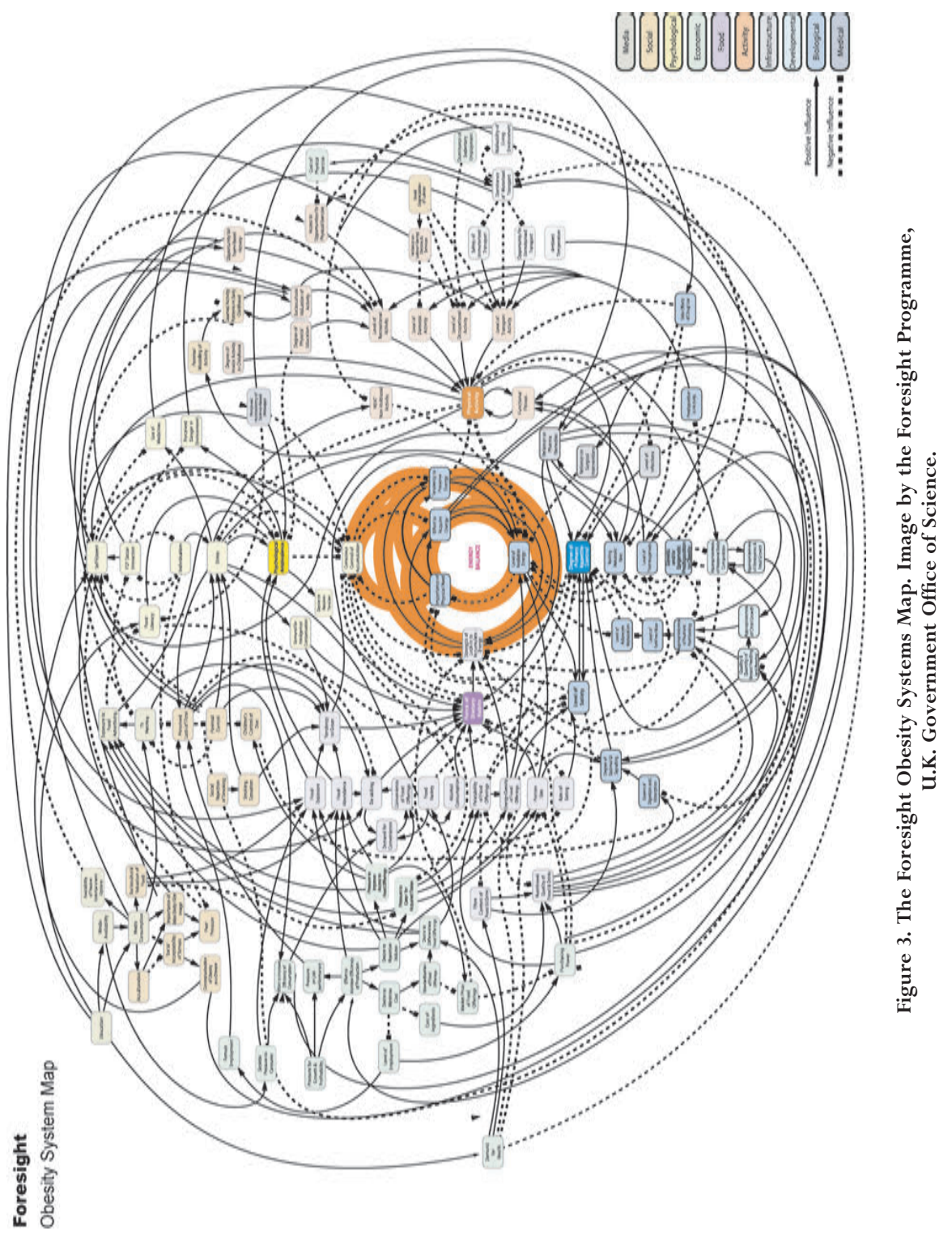


hand, views complexity as endless and impossible to know fully (Law 2004). Within baroque complexity, it is not possible to arrive at an emergent overview of the determinants and factors affecting a complex system given the lack of final coherence and the existence of only partially mappable connections and uncertain relations between different factors. In Kwa's (2002, 47) words, uncertainty in the baroque reading of complexity is ontological rather than epistemological. Ulijaszek shows how the complexity of obesity's determinants became reduced to a romantic framing, which places the energy balance at the center of the model, obscuring or displacing other possible framings (such as gene-environment interactions, food production, and distribution or macroeconomic factors influencing food choice). In his view, this resulted from the British Government Office for Science explicitly charging the Foresight Project with producing a view of obesity control that could be politically tractable (Ulijaszek 2015). This makes evident the relation between framings of complexity, definitions of the knowable (and, by extension, what is not known or ignored), and the (state) politics of operationalizing knowledge.

At stake is how to make emerging knowledge — overburdened by its own complexity _ operational. This requires rendering the effects of interventions calculable in accord with the logics of bureaucratic management. For example, Charlotte Biltekoff (Biltekoff et al. 2014, 22) argues that "charismatic nutrients" have helped render nutritional problems (such as micronutrient deficiencies, excess lipids, or simple carbohydrates) calculable. Charismatic nutrients index more than nutrition, in that they also carve out an evidentiary space for advocates to rally (wittingly or not) behind specific nutritional interventions in a context where nutritional experts need to "satisfy increasingly quantification-oriented parameters." Much of the scholarship in the area of evidence-based policy focuses on the difficulties of knowing complex realities, but less has focused on the way in which complexity and uncertainty are both productive and actively produced. In the final section, I examine how certain facts concerning obesity or public health nutrition interventions come to rally more support and visibility than others.

\section{FROM SCIENTIFIC UNCERTAINTY TO STRATEGIC IGNORANCE}

In their analysis of the effects of corporate behavior on public health, Moodie and colleagues (Moodie et al. 2013, 671) propose the term industrial epidemic to refer to the spread of disease caused by "corporate disease vectors." The authors express concern over the call for multisectoral action, to include the private sector and industry, by the UN's High-Level Meeting on Non-Communicable Diseases. 
This call makes public-private partnerships central to the development of public health policy. Public-private partnerships are often heralded as holding the potential to improve health globally, but Moodie and colleagues (Moodie et al. 2013, 670) point out that the unhealthy commodities actively promoted by the private partners constitute major drivers of global noncommunicable disease (NCD) epidemics. They therefore conclude that these industries should play no role in the formation of NCD policy and that "public regulation and market intervention are the only evidence-based mechanisms to prevent harm caused by the unhealthy commodity industries." Likewise, a group of 150 organizations made a declaration (Public Interest Civil Society Organizations and Social Movements Forum 2014) at the aforementioned International Conference on Nutrition in Rome, urging member states to ensure the proper regulation and accountability of transnational corporations whose practices interfere with the enjoyment of the human right to adequate food. In particular, they called attention to the fact that agroindustrial food systems have contributed to various forms of malnutrition at stake in their discussions and argued that there is a need to protect the policy space of governments against conflicts of interest introduced by inappropriate relationships with "powerful economic actors." Corporate influences on public policy have become the object of an emerging subfield of public health concerned with systematically analyzing the effects of corporate behavior on health. Moodie and colleagues (Moodie et al. 2013) methodically review the ways in which industries avoid regulation and shape policy agendas through a range of techniques. These include biasing research findings, co-opting policymakers, lobbying to oppose public regulation, circulating blame-the-victim approaches to health promotion, and denouncing so-called nanny-state interventions. "As an alternative to regulatory measures," Moodie and colleagues (Moodie et al. 2013, 674) explain, "industries promote ineffective individually-targeted information and educational approaches." Examining the incursion of market actors into French public health programs, Henri Bergeron, Patrick Castel, and Etienne Nouguez (2013, 285) note that the framing of obesity in the current version of the PNNS proves even less unfavorable to industrial interests. As the communications director of one agroindustrial health promotion partner told them, "education about consumption behaviors" is a positive solution to public health problems, while "regulatory or legal constraints," such as "abusive taxation or the banning of advertisement," do not prove effective. Such a statement is astounding and points to how the notion of efficacy has itself been transformed by the kind of evidentiary regimes that are in place after decades of industry-funded research. In a workshop hosted by Lille's 
Institut Pasteur Nutrition Service in 2013, the then-director of the French Advertising Regulation Authority was invited to a roundtable discussion on childhood obesity. He stated that the industries he represented awaited solid preuves scientifiques (scientific evidence) linking product advertisements to children with increased rates of obesity. In the absence of such causal demonstrations, he saw no reason for industry to unilaterally assume the responsibility for "all of society's ills." Obesity is primarily "an educational problem," he concluded, alluding to parental responsibilities. While the director's position was entirely predictable, what surprised me was the complete lack of response from his copanelists and from the assembly of more than 150 health professionals and educators. As my colleagues at the WPHNA often remark, the burden of proof weighs more heavily on the side of those who contest the status quo around how evidence is mobilized for policy.

Selda Ulucanlar and colleagues (Ulucanlar et al. 2014) propose the term evidential landscaping to describe how transnational tobacco corporations misrepresent scientific evidence. They systematically review strategies deployed by the tobacco industry to change the evidential landscape within which the policy debate is conducted, which include misquoting published evidence, mimicking scientific critique, and introducing and promoting alternative research, in particular behavioral studies of individuals rather than assessments of population-scale interventions. Examples of evidence landscaping in the field of obesity research include the recurrent tipping of the balance of blame toward sugars, fats, or sedentary behavior. These research agendas have been linked, respectively, to dairy or sugar consortia that fund research programs downplaying the deleterious health impacts of their products, as one senior nutritionist explained to me in an interview. In a presentation given at the annual conference of a large French public-private research consortium on the levers for nutritional behavior change, a senior civil servant from the Direction Générale de la Santé outlined the changing role of the PNNS since its inception in 2001. While "informing" and "educating" remain central, new policies "implicating stakeholders" (a euphemistic term for the private sector) have been added. He emphasized how this new policy instrument served as a guarantee of the "scientific validity of nutritional information." By signing voluntary agreements to improve the nutritional profile of their products (such as by lowering salt or sugar content), industrial stakeholders can use the PNNS logo in their advertisements. When questioned by a member of the audience about how health claims were assessed - given the controversial nature of such knowledge - the civil servant responded that there was "no controversy over what 
a good diet includes." He added that it was essential to move past conspiracy thinking and that the PNNS considered the food industry incontournables (indispensable) stakeholders in the promotion of healthy eating. The tone was tense and the chair rapidly moved the debate to a technical discussion about measuring the efficacy of PNNS interventions. The voluntary PNNS agreements have the advantage of being simultaneously cheap for the state and remarkably unaggressive toward the food industry (Bergeron, Castel, and Nouguez 2013). Voluntary selfregulation has been heavily critiqued for its inefficiency (see, especially, Moodie et al. 2013). In French health policy circles, a widely circulating public secret (cf. Taussig 1999), discussed over coffee between sessions, is that the state can do very little to tackle obesity given that the agroindustry remains the nation's largest employer. As a cardiologist I interviewed explained: “C'est la crise [it's a time of crisis], and governments are terrified of delocalization. They can't do much because the agroindustrial lobbies are too powerful." While this dilemma is not specific to France, what seems notable here is the absence of debate around conflicts of interest and lobbying practices in public health nutrition. ${ }^{9}$

The emphasis placed on measures of efficacy and quantified évaluations d'impacts (impact evaluations) in these expert circles is striking given the inefficiency of individual-focused IEC interventions. Take the concept of the obesogenic environment. Presentations on the subject are principally concerned with the methodological difficulties of modeling how urban settings shape eating behaviors. One health geographer presented her exploratory results at the aforementioned conference on the levers for nutritional behavior change and opened with a tellingly cynical remark: "I don't have a Conflict of Interest slide because industry isn't interested in geographers yet, but I love Ferrero Rochers.” She went on to present research on the use of GPS to "objectively measure people's exposures to their environments." The project purports to map people's daily trajectories through urban spaces to evaluate the impact of food offerings on individual consumption behaviors. Yet things get tricky when establishing indicators or proxies for un/healthiness. The speaker noted that, in North American obesogenic environment studies, proximity to a supermarket is taken as a proxy for healthy eating, an assumption that did not carry through to the French context, in which supermarkets remain associated with unhealthy eating. Beyond revealing the at times arbitrary nature of such indicators, particularly as they travel, the case of this presentation demonstrates the promissory value that quantifiable interventions hold, even when they are founded on methodologically dubious frameworks. 


\section{CONCLUSION}

Risks caused by individual behaviors have been an overstated concern in public health. Individual behavior has been identified as a critical locus of intervention, largely because these interventions are cheap and comparatively easy to implement. But this approach obscures a range of things, such as the contested nature of the knowledge transferred and the ways in which uncertainty may not simply be an inherent product of complexity but can also be strategically produced. I have highlighted the disproportion between exhortations to healthy eating aimed at individual consumers and the remarkable laissez-faire that characterizes how the food and drink industries are invited to voluntarily limit fat, sugar, or salt in their products. In a world of uncertainties and contested knowledges, knowing does not constitute a clearly identifiable endpoint. Knowledge does not proceed linearly from the absence of knowledge (or ignorance) to knowing. The focus on knowing latent in health education is based on a presumption of ignorance that overshadows the variegated forms of not-knowing at play in the field of public health nutrition. New social marketing versions of health education emphasize individual responsibility to consume in particular ways. These campaigns tend to be conducted at the expense of truly multisectoral regulatory interventions across agricultural and nutritional policy domains. Interventions in public health nutrition often operate on a mechanistic model of goal realization. At stake here is the capacity to intervene in an operational manner, as well as to define the kinds of knowledges that enable intervention. Where the public health response to the problem of obesity is concerned, the difficulty of implementing measurably effective interventions is both a problem for action and an endless resource to fuel further action (Sanabria and Yates-Doerr 2015).

Carlo Caduff $(2014,304)$ argues that while the attempted escape from the "knowledge machine" of late liberalism constituted an important move, simply turning to its underside - unknowing — locks social science into a dialectics of the un/known. I have traced the loopings that operate between regimes of knowing and unknowing not so much to know more about unknowing as to reveal the politics of ascribing knowledge or its absence to specific groups or evidencemaking practices.

I have also aimed to consider how such circulations affect possible registers of public action. In mapping the relations between complexity, uncertainty, and knowledge in public health, my concern has been to consider the spaces for intervention carved out in the field of obesity. The problem of obesity's complexity conceals an assumption about the possibility of developing efficient inter- 
ventions through the accumulation of evidence and the computing, scaling up, or translating of this evidence into replicable practices of prevention or care. The implicit idea here is that we need more evidence, more knowledge, and more powerful computational tools and models to link the types of evidence produced, from the genetic to the individual to the community scale to the realm of global policy.

An important epistemological question remains concerning the kinds of things that can be known and the relation between knowledge and action. Interrogations along these lines have much to gain by considering not only what can be known and what can be established as a valid regime of proof, but also what is actively made unknown or unknowable. The evidentiary exigencies around the implementation and evaluation of public health nutrition interventions are such that crucial phenomena are ignored or rendered irrelevant. This is not because we do not know enough, as is often claimed in public health nutrition conferences, but because existing forms of scientific evaluation make it impossible for certain things to be known, for certain relations to be causally established.

Rather than questioning the forms that evidentiary practices have takenas in the request for preuves (proof) of causal linkages — we are witnessing a diffuse, but increasingly consensual rhetorical move toward the language of uncertainty. Working alongside my colleagues at the WPHNA, I find myself wondering about their desire to build sounder scientific evidence for the socially and environmentally sustainable alternatives that we hope to see reshape the current profit-driven food system. How, I wonder, can a knowing specific to ethnographic practice be leveraged to inflect how the knowable is framed in public health? I have argued here that making noncausal and nonlinear relations visible is something that the practice of ethnography is uniquely equipped to do. Ethnography can see through contemporary habits of framing complex conditions, untangling with its exacting specificity the tightly coupled technical (and ideological) systems typical of what Kim Fortun (2012) has called late industrialism.

\begin{abstract}
This article examines what is said to be un/known about obesity and the ways in which attributions of knowledge or ignorance circulate in the field of public health nutrition. Risks caused by individual behaviors have been an overstated concern in public health. Obesity, like many of today's complex problems, is determined by myriad nested interactions spanning the political economies of market regulation, modes of agricultural production, the biochemistry of appetite regulation, and chang-
\end{abstract}


ing family structures. Yet public intervention - and the science produced to validate it - remains wedded to a mode of intervening that has limited purchase on the complexity with which it contends. This article draws on scholarship on the social construction of ignorance to argue that the field of evidence in obesity science is fashioned in a way that deflects attention (and responsibility) away from questions of food production and marketing and continues to frame the problem as one of individual responsibility. Rather than discrediting the veracity of evidence produced out of industry-research partnerships that increasingly dominate public health research, this article examines how the field of evidence has been structured by these relations. It argues that the demonstration of causal relations between political and socioeconomic determinants of malnutrition and measurable health indexes is largely impossible, not simply because of the absence of good evidence but because the existing parameters of good science cannot straightforwardly reveal such relations. This, in turn, is due to the configuration of the knowable in terms of whether knowledge can be made operational. [obesity; ignorance; scientific evidence; complexity; France]

\section{NOTES}

Acknowledgments My thinking on scientific evidence, complexity, conflicts of interest, and strategic ignorance owes much to the exchanges in which I am lucky to be engaged with colleagues at the World Public Health Nutrition Association. The ideas developed here germinated in the context of the "Producing Knowledge, Governing Populations" conference held at the Ecole Normale Supérieure de Lyon in September 2013, and I am particularly grateful to Charlotte Brives and Frédéric Le Marcis for the sustained conversations that grew out of this event. The argument was much improved thanks to the feedback I received at the Centre de Sociologie des Organisations seminar, Sciences Po, Paris (October 2014) and the "Knowledge/Value, Dark Data and Absences" workshop held in Exeter (December 2014). I am particularly grateful to the insightful and engaged comments that Dominic Boyer, Anita Hardon, Kaushik Sunder Rajan, and Emily Yates-Doerr provided on earlier drafts of this article.

1. This meeting of the Food and Agriculture Organization and the World Health Organization was held in Rome in November 2014. It brought together United Nations representatives, civil society organizations, and the agrofood industry.

2. This footnote, along with others that provided technical definitions of healthy diets, were scratched in the final ratified declaration after the United States and several European delegations raised concerns about wording.

3. These were the words of the Nigerian minister for agriculture at ICN2.

4. Situating the French response to obesity within a comparative analysis of international policy responses to the issue lies beyond the remit of this article. Such a project would need to engage with the imaginaries produced through geographically localized representations of national specificities (think of the "Mediterranean diet," the "French paradox," the "Americanization of the food system," and so on) as they circulate in international spaces.

5. Les trois-huits refers to a system of three eight-hour shifts that enables factories to function twenty-four hours a day but is deeply disruptive to chronobiological systems as workers oscillate between day and night shifts several times a week.

6. Mutuelles are not-for-profit organizations that provide health insurance to meet health costs not covered by the state national security system.

7. Even the extreme-right party le Front National defends access to national health services for all "French." The concept of social security itself is not questioned. 
8. Substitutionism involves substituting farm-based commodities with manufactured ones. It has been taken to new levels as emulsifiers, transfats, and high-fructose corn syrup stand in for plant and animal foods, lowering quality and cost while increasing profit margins (Guthman 2015, 8).

9. The French political system is founded on the ideal that no institutions come between the state and its citizens. This has impeded the development of transparent consultation procedures by which the roles of intermediate organizations that do lobby parliamentarians are spelled out.

\section{REFERENCES}

Adams, Vincanne

2013 "Evidence-Based Global Public Health: Subjects, Profits, Erasures." In When People Come First: Critical Studies in Global Health, edited by João Biehl and Adriana Petryna, 54-90. Princeton, N.J.: Princeton University Press.

Bergeron, Henri, Patrick Castel, and Étienne Nouguez

2013 “Éléments pour une sociologie de l'entrepreneur-frontière. Genèse et diffusion d'un programme de prévention de l'obésité." Revue Française de Sociologie 54, no.

Berlant, Lauren 2: 263-302. http://dx.doi.org/10.3917/rfs.542.0263.

2011 Cruel Optimism. Durham, N.C.: Duke University Press.

Bes-Rastrollo Maira, Matthias B. Schulze, Miguel Ruiz-Canela, and Miguel A. Martinez-

Gonzalez

2013 "Financial Conflicts of Interest and Reporting Bias regarding the Association between Sugar-Sweetened Beverages and Weight Gain: A Systematic Review of Systematic Reviews.” PLOS Medicine, December 31. http://dx.doi.org/ 10.1371/journal.pmed. 1001578 .

Biagioli, Mario

Forthcoming Strange Appropriations: Plagiarism and Ghostwriting in Science.

Biltekoff, Charlotte, Jessica Mudry, Aya H. Kimura, Hannah Landecker, and Julie Guthman

2014 "Interrogating Moral and Quantification Discourses in Nutritional Knowledge." Gastronomica 14, no. 3: 17-26. http://dx.doi.org/10.1525/gfc. 2014.14.3.17.

Brownell, Kelly D., and Mark S. Gold

2012 Food and Addiction: A Comprehensive Handbook. Oxford: Oxford University Press. Caduff, Carlo

2014 "Pandemic Prophecy, or How to Have Faith in Reason." Current Anthropology 55, no. 3: 296-315. http://dx.doi.org/10.1086/676124.

Croissant, Jennifer L.

2014 "Agnotology: Ignorance and Absence or Towards a Sociology of Things That Aren't There.” Social Epistemology 28, no. 1: 4-25. http://dx.doi.org/10.1080/ 02691728.2013 .862880$.

Fitzpatrick, Katie, and Richard Tinning

2014 Health Education: Critical Perspectives. Oxford: Routledge.

Fortun, Kim

2012 "Ethnography in Late Industrialism." Cultural Anthropology 27, no. 3: 446-64. http:/ /dx.doi.org/10.1111/j.1548-1360.2012.01153.x.

Frickel, Scott, and Michelle Edwards

2014 "Untangling Ignorance in Environmental Risk Assessment." In Powerless Science? The Making of the Toxic World in the Twentieth Century, edited by Soraya Boudia

Gard, Michael and Nathalie Jas, 215-33. New York: Berghahn Books.

2011 "Truth, Belief, and the Cultural Politics of Obesity Scholarship and Public Health Policy.” Critical Public Health 21, no. 1: 37-48. http://dx.doi.org/10.1080/ 09581596.2010 .529421$. 
Geissler, P. W.

2013 "Public Secrets in Public Health: Knowing not to Know while Making Scientific Knowledge." American Ethnologist 40, no. 1:13-34. http://dx.doi.org/10.1111/ amet.12002.

Gornall, Jonathan

2015 "Sugar: Spinning a Web of Influence." BMJ 350, February 11. http://dx.doi. org/10.1136/bmj.h231.

Gross, Matthias, and Linsey McGoey, eds.

2015 Routledge International Handbook of Ignorance Studies. London: Routledge.

Guthman, Julie

2015 "Binging and Purging: Agrofood Capitalism and the Body as Socioecological Fix." Environment and Planning A 47. http://dx.doi.org/10.1068/a140005p.

Hawkes, Corinna, and Kent Buse

2011 "Public Health Sector and Food Industry Interaction: It's Time to Clarify the Term 'Partnership' and Be Honest about Underlying Interests." European Journal of Public Health 21, no. 4: 400-403. http://dx.doi.org/10.1093/eurpub/ ckr077.

Heimer, Carol A.

2012 "Inert Facts and the Illusion of Knowledge: Strategic Uses of Ignorance in HIV Clinics." Economy and Society 41, no. 1: 17-41. http://dx.doi.org/10.1080/ 03085147.2011 .637332 .

Herrick, Clare

2009 "Shifting Blame/Selling Health: Corporate Social Responsibility in the Age of Obesity." Sociology of Health \& Illness 31, no. 1: 51-65. http://dx.doi.org/ 10.1111/j.1467-9566.2008.01121.x.

Hess, David J.

2015 "Undone Science and Social Movements: A Review and Typology." In Routledge International Handbook of Ignorance Studies, edited by Matthias Gross and Linsey McGoey, 141-54. London: Routledge.

Ingold, Tim

2014 “That's Enough about Ethnography!” Hau: Journal of Ethnographic Theory 4, no. 1: 383-95. http://dx.doi.org/10.14318/hau4.1.021.

Jasanoff, Sheila

2005 Designs on Nature: Science and Democracy in Europe and the United States. Princeton, N.J.: Princeton University Press.

Kahneman, Daniel

2011 Thinking, Fast and Slow. New York: Farrar, Straus, and Giroux.

Kelly, Ann H., and Uli Beisel

2011 "Neglected Malarias: The Frontlines and Back Alleys of Global Health." Biosocieties 6, no. 1: 71-87. http://dx.doi.org/10.1057/biosoc.2010.42.

Kessler, David A.

2009 The End of Overeating: Taking Control of our Insatiable Appetite. New York: Rodale.

Kleinman, Daniel Lee, and Sainath Suryanarayanan

2015 "Ignorance and Industry: Agrichemicals and Honey Bee Deaths." In Routledge International Handbook of Ignorance Studies, edited by Matthias Gross and Linsey

Kwa, Chunglin McGoey, 183-91. London: Routledge.

2002 "Romantic and Baroque Conceptions of Complex Wholes in the Sciences." In Complexities: Social Studies of Knowledge Practices, edited by John Law and Landecker, Hannah Annemarie Mol, 23-52. Durham, N.C.: Duke University Press.

2013 “Postindustrial Metabolism: Fat Knowledge.” Public Culture 25, no. 3: 495-522. http://dx.doi.org/10.1215/08992363-2144625. 
Law, John

2004 "And If the Global Were Small and Noncoherent? Method, Complexity, and the Baroque." Environment and Planning D 22: 13-26. http://dx.doi.org/10.1068/ d316t.

McGoey, Linsey

2007 "On the Will to Ignorance in Bureaucracy." Economy and Society 36, no. 2: 212 35. http://dx.doi.org/10.1080/03085140701254282.

2012 "Strategic Unknowns: Towards a Sociology of Ignorance." Economy and Society 41, no. 1: 1-16. http://dx.doi.org/10.1080/03085147.2011.637330.

Moodie, Rob, David Stuckler, Carlos Monteiro, Nick Sheron, Bruce Neal, Thaksaphon

Thamarangsi, Paul Lincoln, and Sally Caswell

2013 "Profits and Pandemics: Prevention of Harmful Effects of Tobacco, Alcohol, and Ultra-Processed Food and Drink Industries." Lancet 381, no. 9867: 670-79.

Nutbeam, Don http://dx.doi.org/10.1016/S0140-6736(12)62089-3.

2005 "What Would the Ottawa Charter Look Like if It Were Written Today?" Reviews of Health Promotion and Education Online. http://www.iuhpe.org/rhpeo/ reviews/2005/19/index.htm.

Oreskes, Naomi, and Erik M. Conway

2011 Merchants of Doubt: How a Handful of Scientists Obscured the Truth on Issues from Tobacco Smoke to Global Warming. New York: Bloomsbury.

Oullier, Olivier, and Sarah Sauneron

2010 "Nouvelles approches de la prévention en santé publique. L'apport des sciences comportementales, cognitives et des neurosciences." Paris: Centre d'Analyse Stratégique. http://www.ladocumentationfrancaise.fr/rapportspublics/104000139/.

Pinto, Manuela Fernández

2015 "Tensions in Agnotology: Normativity in the Studies of Commercially Driven Ignorance.” Social Studies of Science 45, no. 2: 294-315. http://dx.doi.org/ 10.1177/0306312714565491.

Prentice, Deborah A.

2015 “Targeting Ignorance to Change Behavior." In Routledge International Handbook of Ignorance Studies, edited by Matthias Gross and Linsey McGoey, 266-73. London: Routledge.

Proctor, Robert N.

2011 Golden Holocaust: Origins of the Cigarette Catastrophe and the Case for Abolition. Berkeley: University of California Press.

Proctor, Robert, N., and Londa Schiebinger, eds.

2008 Agnotology: The Making and Unmaking of Ignorance. Stanford, Calif.: Stanford University Press.

Public Interest Civil Society Organizations and Social Movements Forum

2014 "Declaration to the Second International Conference on Nutrition (ICN2), Rome, 21 November 2014.” Development 57, no. 2: 135-40. http://dx.doi. org/10.1057/dev.2014.85.

Rice, Thomas

2013 "The Behavioral Economics of Health and Health Care." Annual Review of Public Health 34: 431-47. http://dx.doi.org/10.1146/annurev-publhealth-031912114353.

Sanabria, Emilia

2015 "Sensorial Pedagogies, Hungry Fat Cells and the Limits of Nutritional Health Education.” BioSocieties 10, no. 2: 125-42. http://dx.doi.org/10.1057/ biosoc.2015.5.

Sanabria, Emilia, and Emily Yates-Doerr

2015 “Alimentary Uncertainties: From Contested Evidence to Policy." BioSocieties 10, no. 2: 117-24. http://dx.doi.org/10.1057/biosoc.2015.17. 
Stuckler, David, Martin McKee, Shah Ebrahim, and Sanjay Basu

2012 "Manufacturing Epidemics: The Role of Global Producers in Increased Consumption of Unhealthy Commodities including Processed Foods, Alcohol, and Tobacco." PLOS Medicine 9, June 26. http://dx.doi.org/10.1371/ journal.pmed.1001235.

Taussig, Michael

1999 Defacement: Public Secrecy and the Labor of the Negative. Stanford, Calif.: Stanford University Press.

U.K. Government Office of Science

2007 “Tackling Obesities: Future Choices." Foresight Programme. https://www. gov.uk/government/collections/tackling-obesities-future-choices\#project-

Ulijaszek, Stanley report.

2015 "With the Benefit of Foresight: Reframing the Obesity Problem as a Complex System." BioSocieties 10, no. 2: 213-28. http://dx.doi.org/10.1057/biosoc. 2015.16.

Ulucanlar, Selda, Gary J. Fooks, Jenny L. Hatchard, and Anna B. Gilmore

2014 "Representation and Misrepresentation of Scientific Evidence in Contemporary Tobacco Regulation: A Review of Tobacco Industry Submissions to the UK Government Consultation on Standardised Packaging." PLOS Medicine, March 25. http: / /dx.doi.org/10.1371/journal.pmed.1001629

Whitehead, Dean, and Fiona Irvine

2011 “Ottawa 25+_-All Aboard the Dazzling Bandwagon'-Developing Personal Skills: What Remains for the Future?" Health Promotion International 26, S2: ii245-52. http://dx.doi.org/10.1093/heapro/dar072. 